\title{
STUDY OF C-S-H DEHYDRATION DUE TO TEMPERATURE INCREASE DURING FIRES
}

\author{
Moisés Martín-Garrido ${ }^{1}$, Sagrario Martínez-Ramírez ${ }^{1, a}$, Gloria Pérez ${ }^{2}$, Ana M. \\ Guerrero $^{2}$ \\ ${ }^{1}$ Instituto de Estructura de la Materia (IEM-CSIC), C/Serrano 121, 28006 Madrid, Spain \\ mmarting16@gmail.com (Moisés Martín-Garrido); sagrario.martinez@csic.es (sagrario \\ Martínez-Ramírez). \\ ${ }^{2}$ Instituto de Ciencias de la Construcción Eduardo Torroja (IETCC-CSIC), C/Serrano \\ Galvache 4, 28029 Madrid, Spain \\ gperezaq@ietcc.csic.es (Gloria Pérez); aguerrero@ietcc.csic.es (Ana M. Guerrero)
}

\section{Declarations of interest: none}

\begin{abstract}
Concrete is one of the most fire-resistant materials, whose resistance depends on the chemical and structural characteristics of the hydrated calcium silicate $(\mathrm{C}-\mathrm{S}-\mathrm{H})$ formed in the hydration and hardening process. However, the structure and composition of this calcium silicate hydrate varies with the time of hydration. The effect of the composition of the calcium silicate on the anhydrous material formed has been studied after subjecting it to an accelerated study of the effect of fire, irradiating it with a $\mathrm{CO}_{2}$ laser. Changes in the composition of C-S-H can lead to changes in the mechanical properties of the cement. Calcium silicate hydrate samples with different chemical composition $(\mathrm{Ca} / \mathrm{Si}$ ratios 1 and 2$)$ as well as different synthesis processes (double decomposition and hydrothermal) were studied.The crystalline phases obtained after heating were identified through micro-Raman spectroscopy, which confirmed the formation of anhydrous calcium silicates with the same $\mathrm{Ca} / \mathrm{Si}$ ratio as the initial one. In $\mathrm{C}-\mathrm{S}-\mathrm{H}$ gels with a $\mathrm{Ca} / \mathrm{Si}$ ratio of over 1.5 , stable $\mathrm{Ca}(\mathrm{OH})_{2}$ was formed. SEM/EDX analysis determined that in the process of heating with the laser, water is lost fast, generating porous structures. Such porosity is higher in materials with a lower $\mathrm{Ca} / \mathrm{Si}$ ratio.
\end{abstract}

Keywords: $\mathrm{C}-\mathrm{S}-\mathrm{H} ; \mathrm{C}_{2} \mathrm{SH}$; micro-Raman; SEM/EDX; fire

\footnotetext{
"Correspondingauthor: Sagrario Martínez-Ramírez, Instituto de Estructura de la Materia, C/Serrano 121, 28006 Madrid; sagrario.martinez@csic.es; Telephonenumber:+34 915616800; Fax number: +34 915645557.
} 


\section{INTRODUCTION}

When concrete is exposed to high temperatures, as in a fire, physical and chemical transformations take place resulting in deterioration of its mechanical properties. This deterioration varies according to the concrete mix proportions and constituents and can be determined by complex physico-chemical transformations occurring during heating ${ }^{[1]}$.

Water evaporation and chemical changes of hydrated products occur in the cementitious matrix that in turn give rise to an increase in porosity and pore size of concrete. Also, micro-cracks appear due to stress in the interface region between the cement matrix and the aggregates. Other effects relate to phase transitions or disintegration of the aggregates, as well as vapour pressure in pores and thermal stresses that give rise to spalling of concrete at high temperature. Among these changes, one of the main effects causing concrete degradation at high temperatures is the dehydration of the cement matrix.

Numerous attempts have been made to understand the complex mechanism of dehydration and the microstructural changes produced in the cement paste after heating by fire ${ }^{[2]}$. Especially important is the beviour of calcium silicate hydrate $(\mathrm{C}-\mathrm{S}-\mathrm{H})$, the major component in hydrated portland cement, is responsible of cement-based materials strength, bindability and durability.

The behaviour of concrete at high temperatures will depend on the structure and chemical composition of the cement and therefore of this calcium silicate hydrate. This depends on the chemical composition of the initial cement, temperature and time of hydration. According to the literature ${ }^{[1,2]}$, chemically bound water loosens from the calcium silicate hydrate above about $110{ }^{\circ} \mathrm{C}$. Although the $\mathrm{C}-\mathrm{S}-\mathrm{H}$ phase maintains its molecular structure up to $300{ }^{\circ} \mathrm{C}$, a clear change in its morphology is observed for this temperature related to an irreversible shrinkage. At $700{ }^{\circ} \mathrm{C}$, this micro-structure is predominantly composed of globules that form upon complete breakage of C-S-H producing anhydrous silicates and losing its binding capacity.

$\mathrm{C}-\mathrm{S}-\mathrm{H}$ gel characteristics are defined, among others, by $\mathrm{Ca} / \mathrm{Si} \mathrm{ratio}^{[3-5]}$. Anhydrous portland cement initially has two silicate phases with different $\mathrm{Ca} / \mathrm{Si}$ ratios, tricalcium silicate $\left(\mathrm{C}_{3} \mathrm{~S}\right)$ with $\mathrm{Ca} / \mathrm{Si}=3$ and dicalcium silicate $\left(\mathrm{C}_{2} \mathrm{~S}\right)$, with $\mathrm{Ca} / \mathrm{Si}=2^{[6]} \cdot \mathrm{C}_{3} \mathrm{~S}$ hydrates first, initially generating a calcium silicate hydrate with a high $\mathrm{Ca} / \mathrm{Si}$ ratio, whereas $\mathrm{C}_{2} \mathrm{~S}$ hydration, which is slower, yields gels with lower $\mathrm{Ca} / \mathrm{Si}$ ratios $^{[7,8]}$. As the calcium available in a cement-based matrix declines at longer hydration times, the C-S-H formed in later age materials has a lower $\mathrm{Ca} / \mathrm{Si} \mathrm{ratio}^{[9]}$, while the water/Si ratio in such materials also varies ${ }^{[7,8]}$.

Different methods were developed to synthesize C-S-H gels with a controlled value of the $\mathrm{Ca} / \mathrm{Si}$ ratio. One of the quickest and most direct methods to achieve this control is the double decomposition method ${ }^{[6]}$. Alternative procedures have nonetheless been prompted by the need for less polluting materials. This is the case of belite (phase $\beta$ $\mathrm{C}_{2} \mathrm{~S}$-high) cements ${ }^{[10]}$, which with a lower calcium content and lower clinkerisation 
temperature generate less $\mathrm{CO}_{2}$ than portland cement during manufacture. That need, along with the pursuit of more sustainable processes, has placed the spotlight on the hydrothermal synthesis of belite cement from waste materials ${ }^{[10-13]}$. The first stage of the hydrothermal $\beta-\mathrm{C}_{2} \mathrm{~S}$ synthesis ${ }^{[14]}$ generates a precursor, $\mathrm{C}_{2} \mathrm{SH}$, with a $\mathrm{Ca} / \mathrm{Si}$ ratio of 2.0 , the initial ratio between the calcium and silicon ions in the majority belite phase $\left(\beta-\mathrm{C}_{2} \mathrm{~S}\right)$ in these cements.

A number of instrumental techniques are presently used in order to determine the $\mathrm{Ca} / \mathrm{Si}$ ratio of C-S-H gels, either directly or indirectly ${ }^{[4-6,15-19]}$. The most widely used method is energy dispersive X-ray analysis (EDX), associated with transmission electron microscopy (TEM). It involves taking a large number of readings (at least 40) on a very small area of the sample to ensure accuracy and the non-inclusion of impurities in the analysis. One of the most prominent indirect techniques is ${ }^{29} \mathrm{Si}$ nuclear magnetic resonance (NMR). This method determines the area under the curve generated by the signals attributable to silicon tetrahedra with different connectivities $\left(Q^{i}\right)$, i,e., $Q^{1}$ or $Q^{2}$ indicates connection with one or two adjacent tetrahedra. The $\mathrm{Ca} / \mathrm{Si}$ ratio is calculated from the NMR curves with the formula proposed by various authors ${ }^{[4,5]}$. Whilst it is one of the most widely used procedures, as it is indirect, it depends on the method applied to analyse the data.

Raman spectroscopy is a very useful technique to study amorphous and crystalline silicates ${ }^{[20-22]}$. Both types of compounds can be formed after the heating process at high temperatures. Raman spectroscopy has been used also to study the composition of cement and concrete after heating. Vetter et $\mathrm{al}^{[23]}$, studied the effect of fire $\left(950^{\circ} \mathrm{C}\right)$ in a concrete structure after 28 days of hydration, finding C-S-H decomposition with the formation of gehlenite $\left(\mathrm{Ca}_{2} \mathrm{Al}_{2} \mathrm{SiO}_{7}\right)$ and both anhydrous silicates $\left(\mathrm{C}_{2} \mathrm{~S}\right.$ and $\left.\mathrm{C}_{3} \mathrm{~S}\right)$. Similar results were found by Pereskova et al. ${ }^{[24]}$, heating a cement concrete matrix with fibre reinforcement until $1200^{\circ} \mathrm{C}$. In this case, in addition to gehlenite, they also identified the presence of pseudowollastonite (CS) and dicalcium silicate $\left(\mathrm{C}_{2} \mathrm{~S}\right)$ as the main phases formed.

Furnace heating has been used by several authors to investigate the thermal changes occurring in concrete at high temperature, while fire heating is usually considered in studies at a structural level ${ }^{[2]}$. Prior studies have proposed using $\mathrm{CO}_{2}$ laser radiation to simulate the effect of fire on cements and concretes ${ }^{[25-30]}$ as the physics of heat generated by photo-physical reactions is similar to the physics of fire. In fact, laser irradiation offers several advantages for this application, including high repeatability of experimental conditions and, most importantly, concentration of a high energy in small areas, thus allowing tests at the micro-scale on small samples ${ }^{[26]}$.

The studies on $\mathrm{CO}_{2}$ laser irradiated cements together with Raman studies, identified the presence of crystalline or amorphous phases depending on the radiation conditions. Amorphous calcium silicate was detected in the lower radiation temperature area, while crystalline calcium silicates in the form of $\mathrm{C}_{2} \mathrm{~S}$ or $\mathrm{C}_{3} \mathrm{~S}$ were observed when higher temperatures were reached. It is expected that the final crystalline phases produced after 
rapid heating would depend on the initial $\mathrm{Ca} / \mathrm{Si}$ ratio of the radiated $\mathrm{C}-\mathrm{S}-\mathrm{H}$ gel. Consequently, the analysis of synthetic C-S-H gels with different nominal $\mathrm{Ca} / \mathrm{Si}$ ratios after laser heating would give rise to significant information for understanding $\mathrm{C}-\mathrm{S}-\mathrm{H}$ gel and its behaviour under a fire event.

The aim of the work has been to study gels with different $\mathrm{Ca} / \mathrm{Si}$ ratios exposed to high temperature processes to simulate a fire process. Then, C-S-H gels with different nominal $\mathrm{Ca} / \mathrm{Si}$ ratios were synthesised using hydrothermal or double decomposition procedures and the anhydrous calcium silicates obtained after fire simulation by rapid heating with $\mathrm{CO}_{2}$ radiation were analysed by different techniques.

\section{EXPERIMENTAL PROCEDURES}

Double decomposition was deployed to synthesise two C-S-H gels with nominal $\mathrm{Ca} / \mathrm{Si}$ ratios of 0.5 and $2.0\left(\mathrm{CSH}^{0.5}\right.$ and $\left.\mathrm{CSH}^{2.0}\right)$. A C-S-H gel with a nominal $\mathrm{Ca} / \mathrm{Si}$ ratio of 2.0 was also synthesised via hydrothermal process to obtain the calcium silicate hydrate $\left(\mathrm{C}_{2} \mathrm{SH}\right)$ from two types of starting materials: commercial laboratory reagents (sample named $\mathrm{C}_{2} \mathrm{SH}$ ) and fly ash, as an industrial by-product (sample named $\mathrm{FA}-\mathrm{C}_{2} \mathrm{SH}$ ). X-ray fluorescence characterisation of the used fly ash (FA) showed it to contain: $19.4 \%$ $\mathrm{SiO}_{2}, 37.6 \% \mathrm{CaO}, 11.2 \% \mathrm{Al}_{2} \mathrm{O}_{3}, 3.0 \% \mathrm{Fe}_{2} \mathrm{O}_{3}, 3.9 \% \mathrm{SO}_{3}$ and $22.1 \%$ loss on ignition at $1000{ }^{\circ} \mathrm{C}$. The samples synthesised are listed in Table 1, along with the synthesis procedure and nominal $\mathrm{Ca} / \mathrm{Si}$ ratio.

Double decomposition synthesis ${ }^{[31-33]}$ was conducted in a glove box with an inert argon atmosphere. The gels were prepared from stoichiometric amounts of $\mathrm{Na}_{2} \mathrm{SiO}_{3} \cdot 5 \mathrm{H}_{2} \mathrm{O}$ and $\mathrm{Ca}\left(\mathrm{NO}_{3}\right)_{2} \cdot 4 \mathrm{H}_{2} \mathrm{O}$ with nominal $\mathrm{Ca} / \mathrm{Si}$ ratios of 0.5 and 2.0. The respective amount of $\mathrm{Ca}\left(\mathrm{NO}_{3}\right)_{2} \cdot 4 \mathrm{H}_{2} \mathrm{O}$ was dissolved in $2 \mathrm{~mL}$ of decarbonated water and added to $16 \mathrm{~mL}$ of decarbonated water containing the respective amount of $\mathrm{Na}_{2} \mathrm{SiO}_{3} \cdot 5 \mathrm{H}_{2} \mathrm{O}$. The solution $\mathrm{pH}$ was adjusted with $\mathrm{NaOH}$ to values of 12.0-12.5.

The $\mathrm{C}_{2} \mathrm{SH}$ precursor was synthesised hydrothermally ${ }^{[34]}$. The starting materials used as sources of silicon and calcium for the synthesis varied. Laboratory grade $\mathrm{SiO}_{2}$ and $\mathrm{CaO}$ with a combined $\mathrm{Ca} / \mathrm{Si}$ ratio of 2.0 were used for the $\mathrm{C}_{2} \mathrm{SH}$ sample, whereas in the FA$\mathrm{C}_{2} \mathrm{SH}$ sample, the source was a fly ash (FA), to which $\mathrm{CaO}$ was added to adjust the initial $\mathrm{Ca} / \mathrm{Si}$ ratio to 2.0. The solids and decarbonated water were mixed in a reactor at a water/solid weight ratio of 3.0. In the subsequent hydrothermal treatment the temperature of the mix was kept at $200{ }^{\circ} \mathrm{C}$ for $4 \mathrm{~h}$ while the solution was stirred constantly. The reactor was then cooled and the solid obtained was filtered and dried at $80{ }^{\circ} \mathrm{C}$.

The four samples obtained were pressed into $15 \mathrm{~mm}$ diameter wafers and exposed to fire heating simulation by continuous $\mathrm{CO}_{2}$ radiation for $2 \mathrm{~s}(\mathrm{CW} \mathrm{CO} 2$ laser $)$ sourced from a Synrad Firestar $\mathrm{t} 80 \mathrm{CO}_{2}$ laser operating at a wavelength of $10.591 \mu \mathrm{m}$ with a $10 \mathrm{P}(20) \mathrm{CO}_{2}$ laser line, as described elsewhere ${ }^{[25]}$. Although the laser features a maximum $80 \mathrm{~W}$ power output, the power used was $6 \mathrm{~W}$, measured with a Synrad PW- 
250 power meter. The thickness of the pellets was different depending on the synthesis method of the sample. It was about $0.5 \mathrm{~cm}$ for the samples hydrothermally prepared and less than $0.1 \mathrm{~cm}$ for the samples prepared by double decomposition method. This was related with the available amount of sample in each case.

The pre-heated samples were characterised on a Bruker AXS D8 Advance X-ray diffractometer with $\mathrm{Cu} \mathrm{K} \alpha$ radiation, a step size of $0.020^{\circ}$ and a $2 \theta$ angle range of $5^{\circ}$ to $60^{\circ}$. The diffractograms were normalised to the most intense signal $\left(2 \theta \approx 29.1^{\circ}\right)$. Post radiation XRD characterization was not possible since the damage was localized in a relatively small area and the considerable amount of powder necessary for XRD analysis was difficult to extract from the damaged section of the samples.

After heating, the samples were analysed in three areas with different appearance: inner, intermediate and outer (Fig S3). A Renishaw inVia confocal micro-Raman spectrometer fitted with a Leica microscope. The spectra were recorded with a $785 \mathrm{~nm}$ diode laser. Five points were analyzed in each area. Ten scans were performed in each point with $12.5 \mathrm{~mW}$ of laser output power at an acquisition time of 10s.Silicon was used to calibrate the wavenumbers.

The heated samples were morphologically and chemically analysed on a Hitachi S-4800 scanning electron microscope fitted with a BRUKER 5030 energy dispersive analyser. Several points were analysed to confirm reproducibility.

\section{RESULTS AND DISCUSSION}

\subsection{ANALYSIS OF PRE-HEATED C-S-H GELS}

The XRD patterns for the pre-heated C-S-H gels are reproduced in Fig. S1 (Supporting information). The diffractograms for the $\mathrm{CSH}^{0.5}$ and $\mathrm{CSH}^{2.0}$ gel samples (Fig. S1a) (Supporting information) contain the reflections characteristic of tobermorite (PDF 00029-0331 for 14-tobermorite, $5 \mathrm{CaO} \cdot 6 \mathrm{SiO}_{2} \cdot 9 \mathrm{H}_{2} \mathrm{O}$ ). The absence of [001] reflection $\left(2 \theta \approx 7.4^{\circ}\right)$, together with the fact that the normalised intensity of the signal at $2 \theta \approx 16.1^{\circ}$ is close to 0.8 , suggests that the experimental $\mathrm{Ca} / \mathrm{Si}$ ratio in both gels is on the order of 0.8 to $1.0^{[35,36]}$.

Table 1.-Synthesis procedure and nominal $\mathrm{Ca} / \mathrm{Si}$ ratio of the samples synthesised

\begin{tabular}{ccc}
\hline Sample & Synthetic procedure & $\begin{array}{c}\text { Nominal Ca/Si } \\
\text { ratio }\end{array}$ \\
\hline $\mathrm{CSH}^{0.5}$ & Double decomposition & 0.5 \\
$\mathrm{CSH}^{2.0}$ & Double decomposition & 2.0 \\
$\mathrm{C}_{2} \mathrm{SH}$ & Hydrothermal with laboratory reagents as & 2.0 \\
FA- & starting materials & 2.0 \\
$\mathrm{C}_{2} \mathrm{SH}$ & Hydrothermal with waste as the starting & material \\
\hline
\end{tabular}


These values are significantly different from their nominal ratio of 0.5 and 2.0 (see Table 1). These results are in line with previous works in which it is described that the $\mathrm{C}-\mathrm{S}-\mathrm{H}$ gel obtained by the double decomposition method has $\mathrm{Ca} / \mathrm{Si}$ ratios close to 1.0, independently of stoichiometric ratios ${ }^{[33]}$.

The diffractogram for the calcium silicate hydrate hydrothermally synthesized from laboratory reagents, $\mathrm{C}_{2} \mathrm{SH}$ (Fig. S1b) (Supporting information), contains $\alpha-\mathrm{C}_{2} \mathrm{SH}$ (PDF 00-029-0373) as the majority phase, along with calcite, $\mathrm{CaCO}_{3}$ (PDF 00-05-0586), and portlandite, $\mathrm{Ca}(\mathrm{OH})_{2}(\mathrm{PDF} 00-044-1481)$ as minority phases and traces of $\mathrm{SiO}_{2}(\mathrm{PDF}$ 00-075-1522). The pattern for the solid synthesized from fly ash ( $\mathrm{FA} \mathrm{C}_{2} \mathrm{SH}$ ) (Fig. S1b) (Supporting information) shows that it has high contents of both calcium silicoaluminate hydrate (PDF 00-032-0151/00-075-1690) and calcium silicate hydrate (PDF 00-015-0641). The formation of these compounds is consistent with the composition of the raw materials used in the hydrothermal process, namely fly ash with high silicon and aluminum oxide contents and a commercial calcium oxide to establish a $\mathrm{Ca} / \mathrm{Si}$ ratio of 2.0. Portlandite and calcite are also detected. These X-ray diffraction findings are in line with those observed by other authors for synthetic dicalcium silicate hydrate ${ }^{[34,37]}$ and suggest a good agreement between the nominal and the experimental $\mathrm{Ca} / \mathrm{Si}$ ratios in these gels.

$\mathrm{C}-\mathrm{S}-\mathrm{H}$ gel with nominal $\mathrm{Ca} / \mathrm{Si}$ ratio 2.0 has been synthesized by two different methods (double decomposition and hydrothermal process) and different XRD diffractograms are obtained for the two products. A more crystalline solid is obtained by hydrothermal synthesis than by the double decomposition method. According to Grangeon ${ }^{[36]}$, different synthesis procedure and/or ageing of C-S-H can lead to different C-S-H structures.

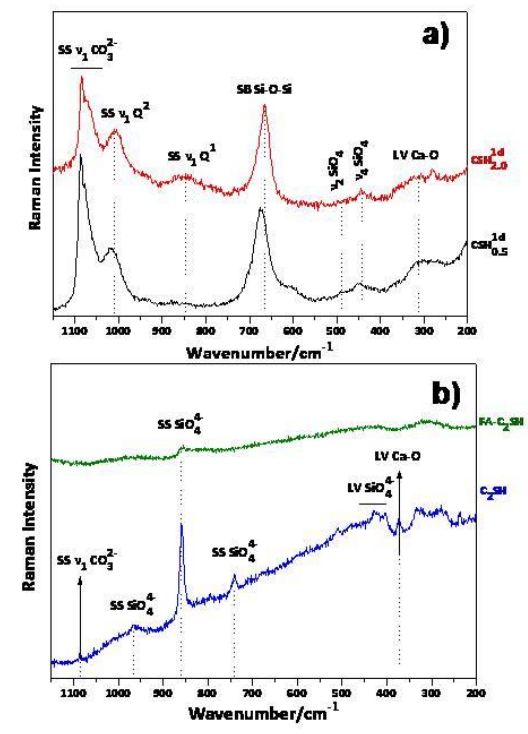

Fig.1.- Micro-Raman spectra, sample in the $1200 \mathrm{~cm}^{-1}$ to $100 \mathrm{~cm}^{-1}$ range, for: a) double decomposition synthesis C-S-H gels $\left(\mathrm{CSH}^{2.0}\right.$ and $\left.\mathrm{CSH}^{0.5}\right)$; b) hydrothermally synthesised $\mathrm{C}_{2} \mathrm{SH}\left(\mathrm{C}_{2} \mathrm{SH}\right.$ and $\left.\mathrm{FA}_{-}-\mathrm{C}_{2} \mathrm{SH}\right)$ $(\lambda=785 \mathrm{~nm})$. ( $\mathrm{SS}=$ symmetrical stretching; $\mathrm{SB}=$ symmetrical bending; $\mathrm{LV}=$ lattice vibration). 
The micro-Raman spectra (Fig. 1a) of the two gels synthesized by the double decomposition method, $\mathrm{CSH}^{0.5}$ and $\mathrm{CSH}^{2.0}$, are quite similar. The most intense signal, at $666 \mathrm{~cm}^{-1}$, is characteristic of the Si-O-Si symmetric bending vibrations in C-S-H gel. That signal shifts to lower wavenumbers at higher $\mathrm{Ca} / \mathrm{Si}$ ratios, denoting a decline in silicate chain length ${ }^{[38]}$. The wide signal observed in the $\mathrm{CSH}^{2.0}$ gel spectrum at $850 \mathrm{~cm}^{-1}$ is attributed to $\mathrm{Q}^{1}$ units, indicating lower polymerisation, i.e., shorter silicate chains than in the gel synthesised with a lower $\mathrm{Ca} / \mathrm{Si}$ ratio $\left(\mathrm{CSH}^{0.5}\right)$. The spectra of the two dicalcium silicate hydrate hydrothermally synthesised $\left(\mathrm{C}_{2} \mathrm{SH}\right.$ and FA- $\mathrm{C}_{2} \mathrm{SH}$, Fig. 1b) exhibit high fluorescence. Consequently, the compounds present in the samples can scarcely be identified, particularly for the gel synthesised from fly ash $\left(\mathrm{FA}-\mathrm{C}_{2} \mathrm{SH}\right)$. Symmetric stretching (SS) vibrations characteristic of a silicate group $\left(966 \mathrm{~cm}^{-1} ; 858\right.$ $\mathrm{cm}^{-1}$ and $742 \mathrm{~cm}^{-1}$ ) and of lattice vibration (LV) $\mathrm{SiO}_{4}{ }^{4-}$ at $425 \mathrm{~cm}^{-1}$ can nonetheless be identified in the $\mathrm{C}_{2} \mathrm{SH}$ sample. A signal observed at $372 \mathrm{~cm}^{-1}$ in the spectrum of that sample was attributed to $\mathrm{CaO}$ network vibrations.

\subsection{ANALYSIS OF HEATED C-S-H GELS}

The photographs in Fig. S2 (Supporting information) depict the wafers made from the $\mathrm{CSH}^{0.5}$ and $\mathrm{CSH}^{2.0}$ gels and the $\mathrm{C}_{2} \mathrm{SH}$ and $\mathrm{FA}-\mathrm{C}_{2} \mathrm{SH}$ precursors after $6 \mathrm{~W} \mathrm{CO}_{2}$ laser radiation for $2 \mathrm{~s}$. Radiation broke the thinner $\mathrm{C}-\mathrm{S}-\mathrm{H}$ gel wafers $\left(\mathrm{CSH}^{0.5}\right.$ and $\left.\mathrm{CSH}^{2.0}\right)$. Fig. S3 (Supporting information) shows different parts of the wafers where the Raman spectra have been measured: inner, intermediate and outer areas.

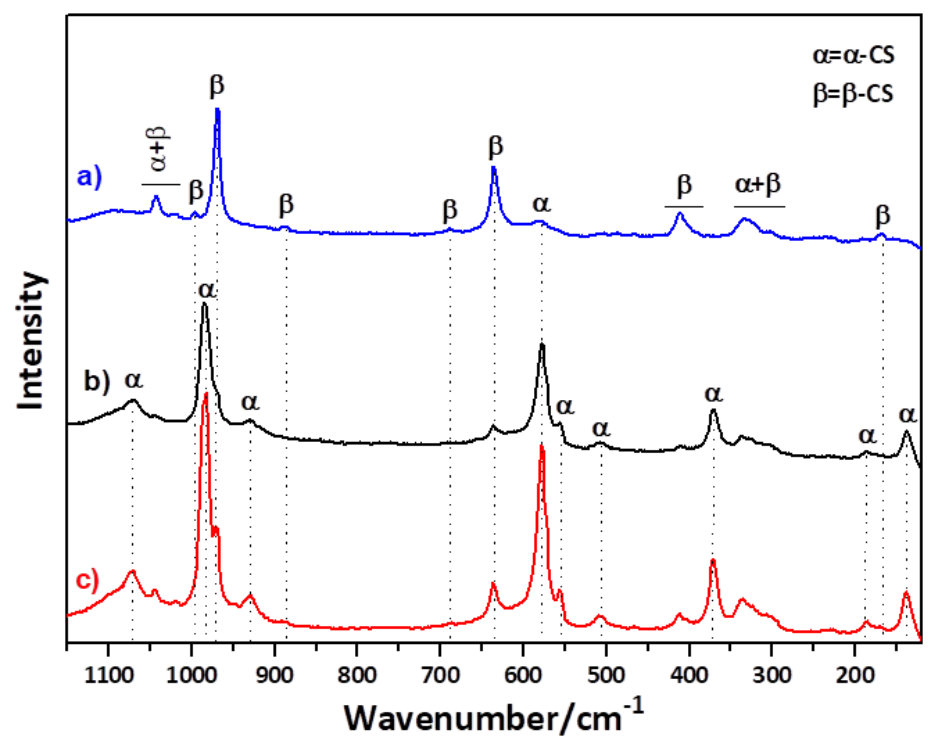

Fig.2.- Micro-Raman spectra, sample in the $1200 \mathrm{~cm}^{-1}$ to $100 \mathrm{~cm}^{-1}$ range, for three points on the $\mathrm{CSH}^{0.5}$ sample after heating: a) outer area; b) intermediate area; c) inner area $(\lambda=785 \mathrm{~nm})$. 
The micro-Raman spectra in the three areas of the heated $\mathrm{CSH}^{0.5}$ gel are shown in Fig. 2. When the cement is exposed to temperatures above $1000^{\circ} \mathrm{C}$ the sample is sintered and its chemical and physical characteristics change ${ }^{[2]}$. From the chemical point of view, two anhydrous calcium silicates with $\mathrm{Ca} / \mathrm{Si}$ ratio of 1.0 are detected, $\alpha-\mathrm{Ca}_{3} \mathrm{Si}_{3} \mathrm{O}_{9}(\alpha-\mathrm{CS})$ and $\beta-\mathrm{CaSiO}_{3}$ ( $\left.\beta-\mathrm{CS}\right)$. It is known that natural calcium silicate has two polymorphs, low temperature wollastonite $(\beta-\mathrm{CS})$, synthesising at around $800^{\circ} \mathrm{C}$, and high temperature pseudowollastonite $(\alpha-\mathrm{CS})$, at around $1200{ }^{\circ} \mathrm{C}^{[39]}$. Both, alpha and beta wollastonite, are present in the three areas of the heated $\mathrm{CSH}^{0.5}$ sample, but alpha phase is predominant in the inner area and beta phase in the outer. The formation of $\alpha$-CS in the inner area of the sample is therefore an indication that the temperature reached there was at least $1200{ }^{\circ} \mathrm{C}$, whilst the presence of $\beta$-CS in the outer, heat dissipation area, attests to temperatures of around $800{ }^{\circ} \mathrm{C}$. Additionally, it should be taken in account that two effects can take place when C-S-H gels are heated: a collapse of the structure or dehydration. In the case of the $\mathrm{CSH}^{0.5}$ sample, prevalence of dehydration effect is observed with formation of dehydrated calcium silicates.

The anhydrous calcium silicate formed after heating of $\mathrm{CSH}^{0.5}$ is wollastonite, with a $\mathrm{Ca} / \mathrm{Si}$ ratio of 1.0, higher than the value used to synthesise this compound. However, as previously discussed, $\mathrm{Ca} / \mathrm{Si}$ ratio of the $\mathrm{C}-\mathrm{S}-\mathrm{H}$ gel in the pre-heated $\mathrm{CSH}^{0.5}$ sample has been identified through XRD to be in the range 0.8-1.0, since there is no shoulder in the signal at $30^{\circ}$, that appears from C-S-H gel with $\mathrm{Ca} / \mathrm{Si}$ ratio $>1$ and the band at $29^{\circ}$ is quite broad ${ }^{[35]}$. If CS (wollastonite or pseudowollastonite) is formed for the samples with $\mathrm{Ca} / \mathrm{Si}$ ratio $<1$, means that an excess of $\mathrm{SiO}_{2}$ it was present in the sample ${ }^{[40]}$. On the other hand, an earlier study by the authors ${ }^{[33]}$ showed experimentally that although the nominal ratio in a double decomposition synthesis was 0.5 , the gel obtained exhibited a $\mathrm{Ca} / \mathrm{Si}$ ratio of nearly 1.0. Formation of an anhydrous calcium silicate with a $\mathrm{Ca} / \mathrm{Si}$ ratio of 1.0 after $\mathrm{CO}_{2}$ laser radiation attests to the elimination of $\mathrm{H}_{2} \mathrm{O}$ from the sample due to rapid localised heating and to the generation of a calcium silicate with a $\mathrm{Ca} / \mathrm{Si}$ ratio of 0.8 to 1.0 , as the initial hydrated phase.

The Raman spectrum of the other C-S-H gel synthesized by double decomposition $\left(\mathrm{CSH}^{2.0}\right)$ after heating is shown in Fig. 3. The spectrum confirms the predominance of the high temperature phase, $\alpha-\mathrm{Ca}_{3} \mathrm{Si}_{3} \mathrm{O}_{9}(\alpha-\mathrm{CS})$ and also contains a double band at 860 and $845 \mathrm{~cm}^{-1}$ characteristic of $\beta-\mathrm{Ca}_{2} \mathrm{SiO}_{4}\left(\beta-\mathrm{C}_{2} \mathrm{~S}\right)^{[41]}$. For the heated $\mathrm{CSH}^{2.0}$ sample, no significant differences are observed with respect to the phases formed in the three zones, except for a higher intensity of the signals corresponding to the $\alpha$-CS phase in the outermost zone of the pellet. As discussed in the aforementioned earlier paper ${ }^{[33]}$, the C$\mathrm{S}-\mathrm{H}$ gel synthesized by double decomposition with a nominal $\mathrm{Ca} / \mathrm{Si}$ ratio of $2.0 \mathrm{had}$ an experimental ratio of 1.1. This behaviour might explain the identification of a majority phase with a $\mathrm{Ca} / \mathrm{Si}$ ratio of 1.0 and a minority phase with a ratio of 2.0 in the heated $\mathrm{CSH}^{2.0}$ sample. No low temperature phase $(\beta-\mathrm{CS})$ is detected in this case, although a compound with a high $\mathrm{Ca} / \mathrm{Si}$ ratio is identified. Again, the highest temperature $\mathrm{CS}$ phase is formed, indicating that a temperature of $1200{ }^{\circ} \mathrm{C}$ was reached in the irradiation process. 


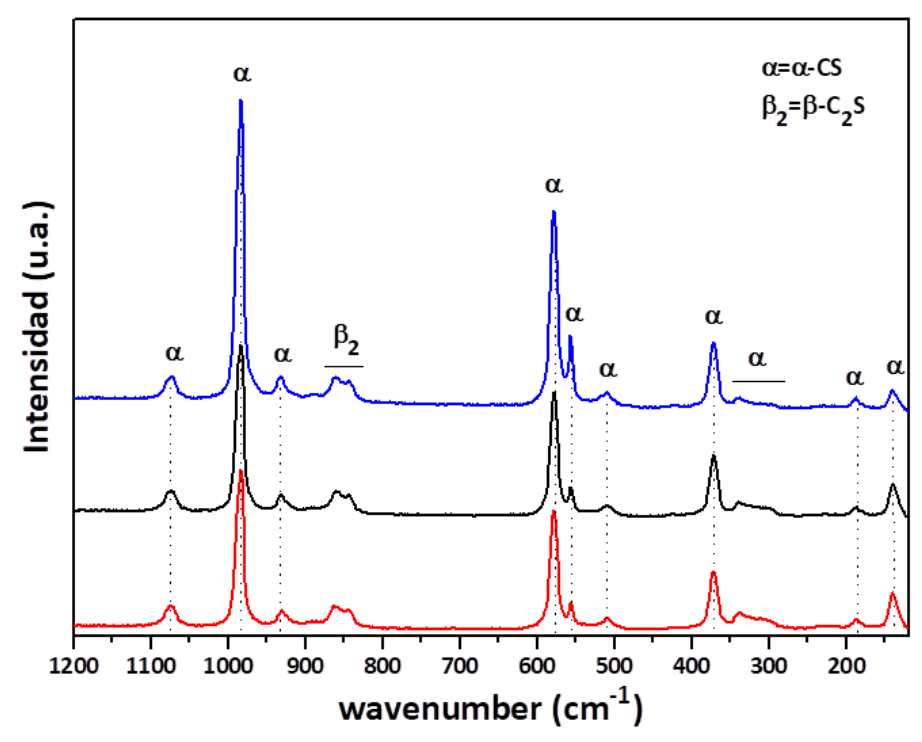

Fig.3.- Micro-Raman spectra, sample in the $1200 \mathrm{~cm}^{-1}$ to $100 \mathrm{~cm}^{-1}$ range, for three points on the CSH${ }^{2.0}$ sample after heating :a) outer area; b) intermediate area; c) inner area $(\lambda=785 \mathrm{~nm})$.

Comparing both samples $\mathrm{C}-\mathrm{S}-\mathrm{H}^{0.5}$ and $\mathrm{C}-\mathrm{S}-\mathrm{H}^{2.0}$, after fire effect, it is interesting to observe that $\beta$-CS is mainly formed after heating the $\mathrm{C}-\mathrm{S}-\mathrm{H}^{0.5}$, while $\alpha$-CS predominates after heating the $\mathrm{C}-\mathrm{S}-\mathrm{H}^{2.0}$. There are several uncertainties about the formation of both wollastonite phases ( $\alpha$-CS and $\beta$-CS) from $\mathrm{C}-\mathrm{S}-\mathrm{H}$ heating, such as the effect of $\mathrm{Ca} / \mathrm{Si}$ ratio, chain length, the presence of other phases, etc ${ }^{[35]}$. In the case of C-S-H $\mathrm{H}^{0.5}$ and C-S$\mathrm{H}^{2.0}$ samples, probably the different chain length observed by Raman spectroscopy, with lower polymerization in the gel synthesised with a higher $\mathrm{Ca} / \mathrm{Si}$ ratio, can promote the different wollastonite phase ( $\alpha$-CS or $\beta$-CS) formation.

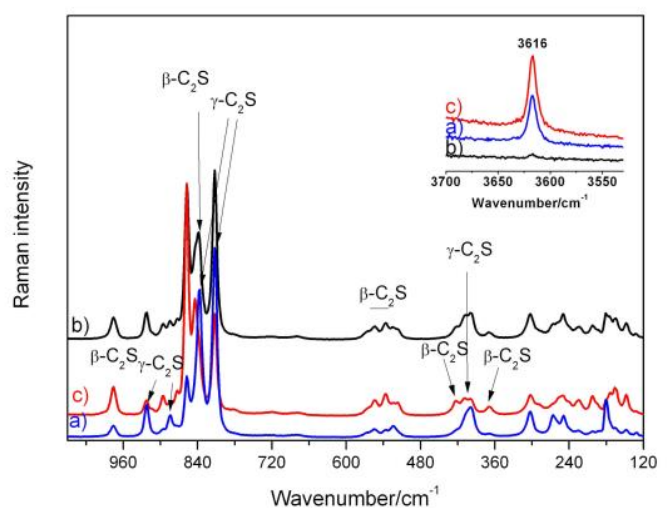

Fig. 4. Micro-Raman spectra sample, in the $1200 \mathrm{~cm}^{-1}$ to $100 \mathrm{~cm}^{-1}$ range, for three points on the $\mathrm{CO}_{2}$ laser-radiated $\mathrm{C}_{2} \mathrm{SH}$ sample synthesised with laboratory reagents:a) outer area; b) intermediate area; c) inner area $(\lambda=785 \mathrm{~nm})$ 
When the $\mathrm{C}_{2} \mathrm{SH}$ synthesised hydrothermally with laboratory reagents was heated, a mix of $\beta-\mathrm{C}_{2} \mathrm{~S}$ and $\gamma-\mathrm{C}_{2} \mathrm{~S}$ was formed (Fig. 4).It is known that the stable dicalcium silicate phase, $\alpha-C_{2} S$, forms at temperature of $1450{ }^{\circ} \mathrm{C}$, evolving towards $\beta-C_{2} S$ if it is cooled quickly or $\gamma-\mathrm{C}_{2} \mathrm{~S}$ if it is cooled more slowly ${ }^{[42-43]}$.

The presence of both polymorphs denotes the existence of areas with different cooling rates: an outer, heat dissipation area where cooling was slower, generating $\gamma-C_{2} S$, and an inner area that cooled more quickly, generating $\beta-\mathrm{C}_{2} \mathrm{~S}$. Moreover, the formation of a calcium silicate from rapidly heated $\mathrm{C}_{2} \mathrm{SH}$ that maintains the same $\mathrm{Ca} / \mathrm{Si}$ ratio as the starting material $(\mathrm{Ca} / \mathrm{Si}=2.0)$ is confirmed by the results.

At $\alpha-\mathrm{C}_{2} \mathrm{SH}$ dehydration temperature $\left(450^{\circ} \mathrm{C}\right)$, the most active phase $\mathrm{x}-\mathrm{C}_{2} \mathrm{~S}$ forms ${ }^{[44]}$. Having increased the temperature, the other active phases such as $\gamma-\mathrm{C}_{2} \mathrm{~S}\left(600^{\circ} \mathrm{C}\right)$ and $\alpha^{\prime}{ }_{L}-C_{2} S\left(800{ }^{\circ} \mathrm{C}\right)$ form, yet also a small amount of inactive $\gamma-C_{2} S$.

The peak at $3616 \mathrm{~cm}^{-1}$ in the Raman spectra of the heated $\mathrm{C}_{2} \mathrm{SH}$ samples (insert in Fig. 4 ) is associated with the vibrations of the $\mathrm{OH}$ group in portlandite. This feature might be attributed to $\mathrm{CaCO}_{3}$ decarbonation and subsequent reaction with water vapour, as noted in earlier papers ${ }^{[28]}$. Georgali and Tsakiridis ${ }^{[45]}$ also observed $\mathrm{Ca}(\mathrm{OH})_{2}$ presence in the inner side of the cement within a reinforced 15-year-old concrete building exposed to fire. In the heating process, water is removed from the $\mathrm{C}-\mathrm{S}-\mathrm{H}$ gel and generates water vapor, which can condense due to the temperature difference between the internal and the external part of the material ${ }^{[1]}$. Subsequent reaction with the $\mathrm{CaO}$ can generate the observed $\mathrm{Ca}(\mathrm{OH})_{2}$. However, other authors ${ }^{[36]}$ contend that nanocrystalline $\mathrm{Ca}(\mathrm{OH})_{2}$ is present in the interlayers of $\mathrm{C}-\mathrm{S}-\mathrm{H}$ gels with high $\mathrm{Ca} / \mathrm{Si}$ ratios (over 1.5). Those portlandite nanocrystals can be released during rapid heating and be detected by Raman spectroscopy. Additionally, the observed $\mathrm{Ca}(\mathrm{OH})_{2}$ must be very stable, as no calcite resulting from the reaction with atmospheric $\mathrm{CO}_{2}$ is detected in the samples, which have not been stored in a $\mathrm{CO}_{2}$-free environment. According to Mendes 2012 ${ }^{[46]}$, the rate of water absorption determines the growth rate and type of $\mathrm{Ca}(\mathrm{OH})_{2}$ crystals formed. Rodriguez-Navarro et $\mathrm{al}^{[47]}$, determine that amorphous calcium hydroxide with both, smaller grain size and larger surface area than crystalline $\mathrm{Ca}(\mathrm{OH})_{2}$, increases carbonation of portlandite. Morsy et $\mathrm{al}^{[39]}$, considered that recrystallization of amorphous portlandite after the heat treatment, produce a stable crystalline $\mathrm{Ca}(\mathrm{OH})_{2}$ which hardly carbonates. As the portlandite observed in the heated $\mathrm{C}_{2} \mathrm{SH}$ sample is not carbonated it can be assumed that it is crystallized in very large crystals with low surface area.

The micro-Raman spectra for $\mathrm{FA}-\mathrm{C}_{2} \mathrm{SH}$ (Fig. 5) after heating contain an intense signal peak at $855 \mathrm{~cm}^{-1}$ with a shoulder at $844 \mathrm{~cm}^{-1}$. The shape of these two peaks differs from the spectra recorded for $\beta-C_{2} S$, where a doublet of sharp peaks at 845 and $856 \mathrm{~cm}^{-1}$ is observed. This behaviour suggests a possible modification of the $\mathrm{C}_{2} \mathrm{~S}$ polymorph. According to Remy et $a l^{[48]}$, the Raman spectrum of $\mathrm{C}_{2} \mathrm{~S}$ contains a signal in the 550$500 \mathrm{~cm}^{-1}$ range from which the polymorph formed can be identified.A wide signal with 
two peaks at $550 \mathrm{~cm}^{-1}$ and $525 \mathrm{~cm}^{-1}$ denotes $\alpha_{\mathrm{L}}{ }^{\prime}-\mathrm{C}_{2} \mathrm{~S}$ formation.If a triple band appears with peaks at $557 \mathrm{~cm}^{-1}, 539 \mathrm{~cm}^{-1}$ and $519 \mathrm{~cm}^{-1}$ the polymorph is dicalcium silicate $(\beta$ $\mathrm{C}_{2} \mathrm{~S}$ ). The presence of three signals detected in the spectra of figure 5 denotes the formation of a mix of the two polymorphs, $\alpha_{L}{ }^{\prime}-C_{2} S$ and $\beta-C_{2} S$. The $\beta-C_{2} S$ polymorph may have stabilised due to the uptake in its structure of minority elements present in the fly ash (FA), precluding its transformation to $\gamma-\mathrm{C}_{2} \mathrm{~S}$ in slower cooling. As shown in the inset of Figure 5, no clear signal from portlandite was observed in this sample.

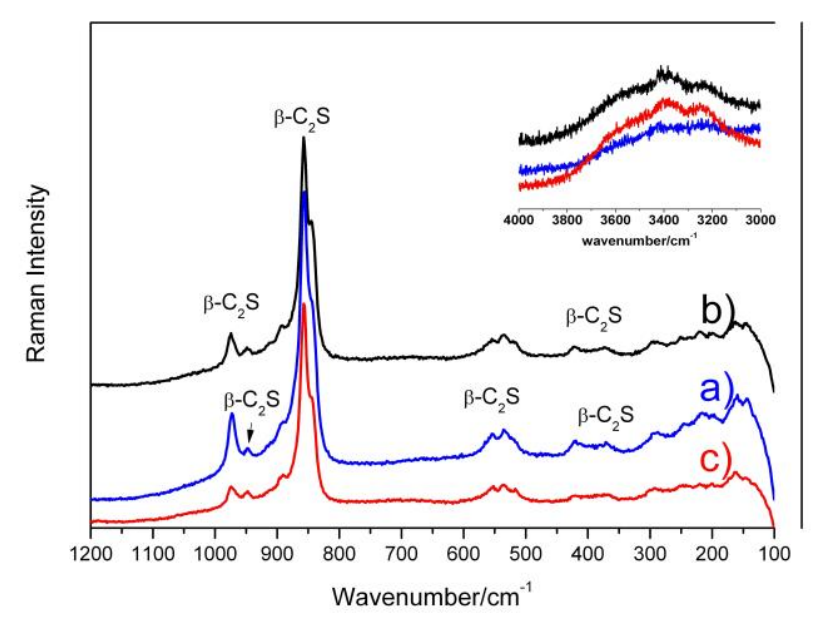

Fig. 5.- Micro-Raman spectra for three points on the $\mathrm{CO}_{2}$ laser-radiated $\mathrm{FA}_{-} \mathrm{C}_{2} \mathrm{SH}$ sample in the $1200 \mathrm{~cm}^{-}$ ${ }^{1}$ to $100 \mathrm{~cm}^{-1}$ range:a) outer area; b) intermediate area; c) inner area $(\lambda=785 \mathrm{~nm})$

The formation of $\mathrm{Ca}(\mathrm{OH})_{2}$ after heating is only observed in the $\mathrm{C}_{2} \mathrm{SH}$ sample, which was the only one initially containing calcite. Therefore, the origin of this portlandite must be that after heating the calcium carbonate generates $\mathrm{CaO}$ which adsorbs ambient water and generates $\mathrm{Ca}(\mathrm{OH})_{2}$, as described previously ${ }^{[28,45]}$.

The SEM/EDX study conducted to complete the analysis of the samples behaviour when exposed to heating yielded the images shown in Fig. 6 a) to d) for the synthetic C$\mathrm{S}-\mathrm{H}$ gels $\left(\mathrm{CSH}^{0.5}\right.$ and $\left.\mathrm{CSH}^{2.0}\right)$ and in Fig. 6 e) to h) for the $\mathrm{C}_{2} \mathrm{SH}$ precursors $\left(\mathrm{C}_{2} \mathrm{SH}\right.$ and FA- $\left.{ }_{2} \mathrm{SH}\right)$.

Table 2.-EDX-determined $\mathrm{Ca} / \mathrm{Si}$ and $\mathrm{Ca} /(\mathrm{Si}+\mathrm{Al})$ ratios in the samples studied

\begin{tabular}{cccccc}
\hline & \multicolumn{3}{c}{$\mathrm{Ca} / \mathrm{Si}$} & \multicolumn{2}{c}{$\mathrm{Ca} /(\mathrm{Si}+\mathrm{Al})$} \\
\cline { 2 - 6 } & Zone 1 & Zone 2 & Zone 3 & Zone 1 & Zone 2 \\
$\mathrm{CSH}^{0.5}$ & $1.46 \pm 0.05$ & $1.27 \pm 0.08$ & & - & - \\
$\mathrm{CSH}^{2.0}$ & $1.51 \pm 0.11$ & $1.72 \pm 0.02$ & $1.70 \pm 0.05$ & - & - \\
$\mathrm{C}_{2} \mathrm{SH}$ & $2.95 \pm 0.45$ & $2.57 \pm 0.19$ & & - & - \\
$\mathrm{FA}_{-} \mathrm{C}_{2} \mathrm{SH}^{*}$ & $2.94 \pm 0.10$ & $2.79 \pm 0.05$ & & $2.17 \pm 0.08$ & $1.20 \pm 0.03$ \\
\hline & $*$ In the FA-C ${ }_{2} \mathrm{SH}$ sample, zone 1 was darker and zone 2 lighter
\end{tabular}


The initial structure of the C-S-H gels synthesized by double decomposition (Fig. 6a and $6 \mathrm{~b})$ is characteristically compact for both nominal $\mathrm{Ca} / \mathrm{Si}$ ratios studied $\left(\mathrm{CSH}^{0.5}\right.$ and $\mathrm{CSH}^{2.0}$ ). After heating, pores are observed in the sample with the lower nominal $\mathrm{Ca} / \mathrm{Si}$ ratio (Fig. 6c), denoting rapid evaporation of the most volatile compounds, probably water. The EDX elemental analysis of the sample shows that the $\mathrm{Ca} / \mathrm{Si}$ ratio in both areas of this sample fluctuats between 1.46 and 1.27. Porosity varies in the sample with a nominal $\mathrm{Ca} / \mathrm{Si}$ ratio of 2.0 (Fig. 6d), while in some areas the structure appears to comprise overlapping layers. Further to the EDX findings, those areas would comprise phases with $\mathrm{Ca} / \mathrm{Si}$ ratios of 1.51 to 1.72 (Table 2), which are higher than those observed in the $\mathrm{CSH}^{0.5}$ samples.
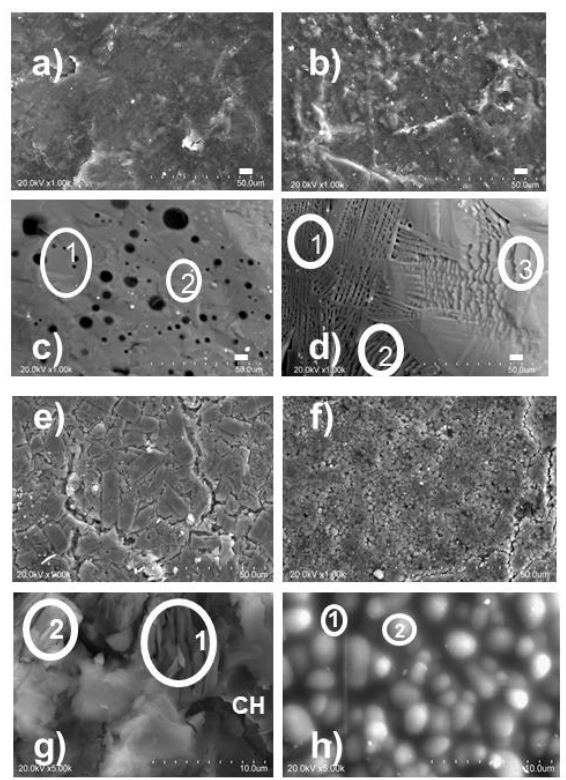

Fig. 6.- SEM/EDX micrographs of a) $\mathrm{CSH}^{0.5}$ before heating; b) $\mathrm{CSH}^{2.0}$ before heating; c) $\mathrm{CSH}^{0.5}$ after heating; d) $\mathrm{CSH}^{2.0}$ after heating; e) $\mathrm{C}_{2} \mathrm{SH}$ before heating; f) $\mathrm{FA}-\mathrm{C}_{2} \mathrm{SH}$ before heating; g) $\mathrm{C}_{2} \mathrm{SH}$ after heating; h) FA- $\mathrm{C}_{2} \mathrm{SH}$ after heating.

(The $\mathrm{Ca} / \mathrm{Si}$ ratios found with EDX analysis of zones 1, 2 and 3 are listed in Table 2.)

Fig. 6e shows that the pre-heated $\mathrm{C}_{2} \mathrm{SH}$ sample has a rectangular structure characteristic of this compound ${ }^{[37]}$. After radiation and water molecule loss (Fig. 6g), the structure is laminar and $\mathrm{Ca}(\mathrm{OH})_{2}$ plates are observed. These observations are consistent with the results of Raman spectroscopy for this sample. Dehydration of the samples after heating is also associated with an increase in porosity (Fig. 6f), as described by Morsay et al. ${ }^{[39]}$ in cement samples heated to study the effect of fire.

From EDX analysis of the heated $\mathrm{C}_{2} \mathrm{SH}$ sample, the $\mathrm{Ca} / \mathrm{Si}$ ratio is determined to be higher than 2.0 (Table 1), possibly indicating that portlandite is also contributing to the signal analysed. The initial $\mathrm{C}_{2} \mathrm{SH}$ sample also has calcite and portlandite and then, the $\mathrm{Ca} / \mathrm{Si}$ ratio determined by SEM/EDX is higher than 2 (Figure 7).

The FA- $\mathrm{C}_{2} \mathrm{SH}$ sample initially has a more or less uniform matrix resulting from wafer compaction. Radiation altered the sample substantially, however, yielding light 
coloured bead-like structures in a dark matrix (Fig. 6h). EDX measurements at ten points in the two zones labelled on the post-heating micrograph of $\mathrm{FA}-\mathrm{C}_{2} \mathrm{SH}$ (Fig.6h) show different composition depending on the zone. From XRD analysis of the initial sample, two phases with different compositions have been identified: one with high content of $\mathrm{Al}\left(\mathrm{Ca}_{3} \mathrm{Al}_{2} \mathrm{SiO}_{4 \mathrm{x}}(\mathrm{OH})_{\mathrm{y}}\right)$ and an aluminium-free phase $\left(\mathrm{Ca}_{2} \mathrm{SiO}_{4} \cdot 0.35 \mathrm{H}_{2} \mathrm{O}\right)$. After heating two phases with different elemental composition determined by EDX are identified: the darker zones, with higher $\mathrm{Al}$ and lower $\mathrm{Si}$ and $\mathrm{Ca}$ signals, as well as the lighter zones in which the Al signal is less intense and the calcium and silicon signals are stronger. As the temperature increases, calcium silicate phases have been formed and something similar may have occurred in this heating process. During heating, the phase rich in $\mathrm{Al}$ would therefore form the matrix, over which the calcium-rich phase would then form. Micro-Raman failed to detect both phases, identifying only the latter (calcium silicate hydrate). Finally, SEM/EDX analysis confirms the absence of portlandite in this sample.

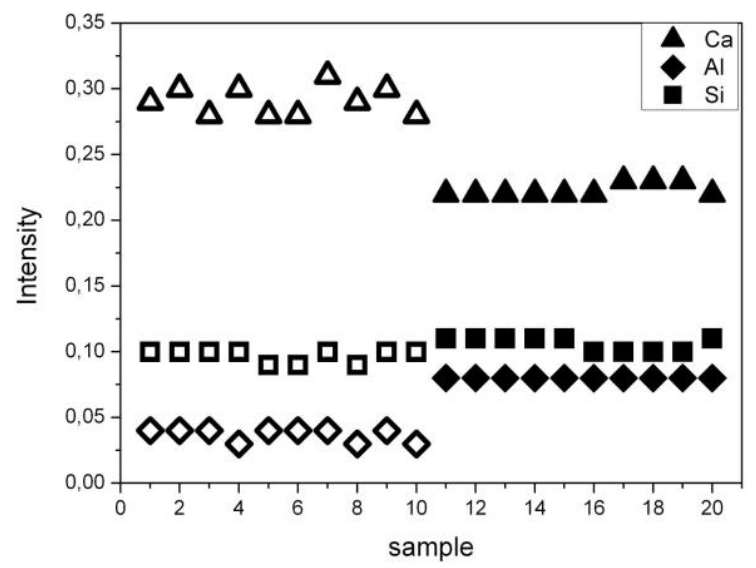

Fig. 7.-EDX-determined $\mathrm{Ca}, \mathrm{Si}$ and $\mathrm{Al}$ in post-radiation $\mathrm{FA}-\mathrm{C}_{2} \mathrm{SH}$ samples (solid figures, dark zones; hollow figures, light zones)

In summary, the micro-Raman and SEM/EDX analysis confirm that diverse synthesis procedures and starting compounds result in C-S-H gels with differing composition and structure. When these gels are submitted to laser radiation to simulate the rapid temperature increase occurring in fire different calcium silicates are formed. In fact, anhydrous compounds generate with a chemical composition similar to the materials used as raw materials in the synthesis of the corresponding C-S-H gel, but in a syntered form. In the process of formation of these materials, water is lost very quickly, generating more porous structures. Such porosity is higher in materials with a lower $\mathrm{Ca} / \mathrm{Si}$ ratio. On the other hand, the $\mathrm{Ca}(\mathrm{OH})_{2}$ formed is less reactive, and therefore, will not carbonate and will not contribute to the increase of mechanical resistances. 


\section{CONCLUSIONS}

Two types of gels with different nominal $\mathrm{Ca} / \mathrm{Si}$ ratios were synthesised using hydrothermal or double decomposition procedures and exposed to continuous $\mathrm{CO}_{2}$ laser radiation to simulate the temperature increase occurring in fires.

The micro-Raman and SEM/EDX analysis of the compounds obtained after heating draw the following conclusions.

- The silicate formed in each sample depends on the initial $\mathrm{Ca} / \mathrm{Si}$ ratio of the heated C-S-H gel and appears in a different polymorphic phase, depending on the temperature reached in each area of the sample. In the area impacted by the laser, where the highest temperature is reached $\left(1200-1400{ }^{\circ} \mathrm{C}\right)$ two varieties of calcium silicates are formed depending on the initial $\mathrm{Ca} / \mathrm{Si}$ ratio: $\alpha$-CS for the samples with $\mathrm{Ca} / \mathrm{Si}$ ratio around 1 and $\alpha-\mathrm{C}_{2} \mathrm{~S}$ when the $\mathrm{Ca} / \mathrm{Si}$ ratio is 2 . In the more distant heat dissipation areas, one of two low temperature anhydrous calcium silicates are formed: $\beta$-CS for lower $\mathrm{Ca} / \mathrm{Si}$ ratios and $\gamma-\mathrm{C}_{2} \mathrm{~S}$ for higher $\mathrm{Ca} / \mathrm{Si}$ ratios.

- After heating the C-S-H gel hydrothermally synthesised with laboratory reagents and an initial $\mathrm{Ca} / \mathrm{Si}$ ratio of 2.0 (sample $\mathrm{C}_{2} \mathrm{SH}$ ) the anhydrous dicalcium silicate with different polymorphs is formed. The two polymorphs, $\beta-C_{2} S$ and $\gamma-C_{2} S$, are formed, due to the existence of areas with different cooling rates: an outer, heat dissipation area where cooling is slower, generating $\gamma-\mathrm{C}_{2} \mathrm{~S}$, and an inner area that cools more quickly, generating $\beta-\mathrm{C}_{2} \mathrm{~S}$. Additionally, in this samples highly stable $\mathrm{Ca}(\mathrm{OH})_{2}$ is formed.

- In the case of radiation of the gel synthesised from a calcium silico-aluminate hydrate, FA- $\mathrm{C}_{2} \mathrm{SH}$, low temperature phase $\beta-\mathrm{C}_{2} \mathrm{SH}$ formation stabilised. Two clearly distinct phases formed in these samples, one $\mathrm{Ca}$ and $\mathrm{Si}$-high and the other $\mathrm{Ca}$ and $\mathrm{Al}$-high. Continuous $\mathrm{CO}_{2}$ laser radiation of synthetic C-S-H gels with different $\mathrm{Ca} / \mathrm{Si}$ ratios yielded an anhydrous calcium silicate that maintained the $\mathrm{Ca} / \mathrm{Si}$ ratio present in the initial gel.

The results of the present work confirm that analysis of laser radiated samples by Micro-Raman spectroscopy is a powerful tool for understanding C-S-H gel composition and structure after heating at high temperatures. Moreover, it allows evaluating the gel $\mathrm{Ca} / \mathrm{Si}$ ratio, separating contributions from silicates and from other phases, like portlandite. This could be an apt method for determining the ratio in C-S-H gels featuring advantages such as the need for only small amounts of sample as well as to evaluate the effect of the fire over the cement composition. Further testing with other types of samples and less aggressive radiation would be required for its optimisation. 


\section{ACKNOWLEDGEMENTS}

This research was funded by the Regional Government of Madrid (CAM) and European Social Fund (Geomateriales 2, S2013/MIT-2914 and TOP-HERITAGE CM (S2018/NMT_4372)) and by the Spanish Ministry of Economy and Competitiveness (FIS2017-84318-R).

Authors would like to thank the CSIC Interdisciplinary Thematic Platform: Open Heritage: Research and Society (PTI-PAIS) for the professional support.

This research did not receive any specific grant from funding agencies in the public, commercial, or not-for-profit sectors.

\section{REFERENCES}

[1] S. Lim and P. Mondal, Mater. Charac. 2014, 92, 15

[2] Q. Ma, R, Guo, Z. Zhao, Z. Lin, K. He. Constr. Build. Mater 2015, 93, 371.

[3] H. Taylor, J. Am. Ceram.Soc. 1986; 69, 464.

[4] I. Richardson, G. Groves, Cem. Concr.Res. 1992; 22, 1001.

[5] I. Richardson, G. Groves, Cem. Concr.Res. 1993; 23, 131.

[6] J. Chen, J. Thomas, H. Taylor, H. Jennings, Cem.Concr.Res. 2004; 34, 1499.

[7] S. Garrault, A.Nonat, Langmuir 2001; 17, 8131.

[8] V. Walker, S. Sutou, C. Oda, M. Mihara, A. Honda, Cem.Concr.Res. 2016; 79, 1.

[9] H. Taylor, Cement Chemistry, Thomas Telford, London, 1997.

[10] I. Jiménez, G. Pérez, A. Guerrero, B. Ruiz, Int. J. Miner. Process. 2017; 158, 8.

[11] K. Pimraksa, S. Hanjitsuwan, P. Chindaprasirt, Ceram. Int. 2009; 35, 2415.

[12] A. Guerrero, S. Goñi, A. Moragues, J. Dolado, J. Am. Ceram.Soc. 2005; 88, 1845.

[13] S. Maheswaran, S. Kalaiselvam, G. S. Palani, S. Sasma, J. Therm. Anal. Calorim. 2016; $125,53$.

[14] M. Georgescu, J. Tipan, A. Badanoiu, D. Crisan, I. Dragan, Cem.Concr.Compos. 2000; 22,315 .

[15] E. Cappelletto, S. Borsacchi, M. Geppi, F. Ridi, E. Fratini, P. Baglioni, J. Phys. Chem. C 2013; 117, 22947.

[16] A. Trapote-Barreira, J. Cama, J. Soler, Phys.Chem. Earth 2014; 70-71, 17.

[17] J. Higl, M. Köhler, M. Lindén, Cem.Concr.Res. 2016; 88,136. 
[18] L. Zhang, X. Cheng, D. Hou, S. Guo, Constr. Build. Mater, 2017; 155, 413.

[19] A. Harris, M. Manning,W.Tearle, C. Tweed, Cem.Concr.Res. 2002; 32, 731.

[20] C. García-Florentino, M. Maguregui, H. Morillas, U. Balziskueta, A. Azcarate, Gorka Arana, J.M.Madariaga, J. Raman Spectrosc. 2016; 47, 1458.

[21] L. Robinet, C. Coupry, K. Eremin, C. Hall, J. Raman Spectrosc. 2006; 37, 789.

[22] M. Torres-Carrasco, A. del Campo, M. A. de la Rubia, E. Reyes, A. Moragues, J. F. Fernández, J. Raman Spectrosc. 2019; 50, 720.

[23] M. Vetter, J. Gonzalez-Rodriguez, E. Nauha, T. Kerr, Constr. Build. Mater. 2019; $204,450$.

[24] Š.Pešková, V.Machovič, P. Procházka, Ceramics - Silikáty 2011; 55, 410.

[25] S. Martinez-Ramirez, L. Diaz, J. J. Camacho, J. Am. Ceram.Soc. 2013; 96, 2824.

[26] M. Gomez-Heras, R. Fort, M. Morcillo, C. Molpeceres, J.L Ocaña, Mater.Construcc. 2008; 58, 217.

[27] K. Kawaka, N. Idris, M. Wada, H. Kurniawan, K. Tsuyuki, S. Miura, Appl. Spectrosc. 2004; 58, 887.

[28] R. Moreno-Virgen, J.J. Soto-Bernal, J. A. Ortiz-Lozano, J. T. Bonilla-Petriciolet, J. T. Vega-Duran, R. Gonzalez-Mota, J. Pineda-Piñón, Mater.Construcc. 2011; 61, 77.

[29] J.A. Lawrence, Wear 2004; 257, 590.

[30] J.A. Lawrence, L. Li, Mater. Sci. Eng.A, 2000; 284, 93.

[31] G. K. Sun, F. J. Young, R. J. Kirkpatrick, Cem.Concr.Res. 2006; 36, 18.

[32] I. García-Lodeiro, A. Fernández-Jiménez, I. Sobrados, J. Sanz, A. Palomo, J. Am. Ceram.Soc. 2012; 95,1440.

[33] M. Martín-Garrido, M. T. Molina-Delgado; S. Martínez-Ramírez, J. Sol-Gel Sci. Technol. 2020; 94, 11.

[34] A. Guerrero, S. Goñi, I. Campillo, A. Moragues, Environ.Sci.Technol. 2004; 38, 3209.

[35] E. Tajuelo-Rodríguez, K. Garbev, D. Merz, L. Black, I. G. Richarson, Cem.Concr.Res. 2017; 93, 45.

[36] S. Grangeon, F. Claret, C. Roosz,TSato, S. Gaboreau, Y. Linard, J. Appl. Cryst. 2016; $49,771$.

[37] K. Garbev, G. Beuchle,M. Bornefeld, L. Black, P. Stemmermann, J. Am. Ceram.Soc. 2008; 91, 3005. 
[38] K. Garbev, P. Stemmermann, L. Black, C. Breen, J. Yarwood, B. Gasharova, J.Am. Ceram.Soc. 2007; 90, 900.

[39] M. M. Morsy,S. S.Shebla, A. M. Rashad, Asian J. Civil Eng. (Building and Housing) 2008; 9, 93.

[40] K. Garbev, M. Bornefeld, G. Beuchle, P. Stemmermann, J. Am. Ceram. Soc. 2009; $91,3015$.

[41] M. Handke, Appl. Spectrosc.1986; 40,871.

[42] C. J. Chan, W. M. Kriven, J. F. Young, J. Am. Ceram. Soc 1992, 75, 1621.

[43] N. Ghosh, P. Bhaskara Rao, A. K. Paul, K. Raina, J. Mater Scienc. 1979, 14, 1554.

[44] M. Stankeviciute, R. Siauciunas, A. Miachai, J. Therm. Anal. Calorim. 2018; 134, 101.

[45] B. Georgali, P.E. Tsakiridis, Cem.Concr.Compos. 2005, 27, 255.

[46] A. Mendes, J. G. Sanjayan, W. P. Gates, F. Collins, Cem.Concr.Compos. 2012; 34, 1067.

[47] C. Rodriguez-Navarro, E. Hansen, W. S. Ginell, J. Am. Ceram. Soc. 1998; 81, 3032 .

[48] C. Remy, B. Reynard, M. Madon ,J. Am. Ceram.Soc. 1997; 80, 413. 

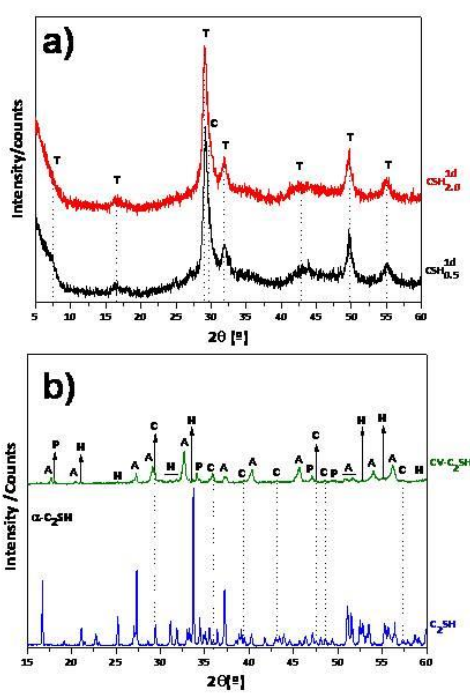

Figure S1. Fig. S1.-XRD patterns for: a) $\mathrm{CSH}^{0.5}$ and $\mathrm{CSH}^{2.0}$; b) $\mathrm{C}_{2} \mathrm{SH}$ and $\mathrm{FA}_{-} \mathrm{C}_{2} \mathrm{SH}(\mathrm{T}=$ $5 \mathrm{CaO} \cdot 6 \mathrm{SiO}_{2} \cdot 9 \mathrm{H}_{2} \mathrm{O} ; \mathrm{H}=\mathrm{Ca}_{2} \mathrm{SiO}_{4} \cdot 0.35 \mathrm{H} 2 \mathrm{O} ; \mathrm{A}=\mathrm{Ca}_{3} \mathrm{Al}_{2}\left(\mathrm{SiO}_{4}\right)_{\mathrm{x}}(\mathrm{OH})_{\mathrm{y}} ; \mathrm{C}=\mathrm{CaCO}_{3} ; \mathrm{P}=\mathrm{Ca}(\mathrm{OH})_{2} ; \alpha=\alpha-$ $\left.\mathrm{C}_{2} \mathrm{SH}\right)$.
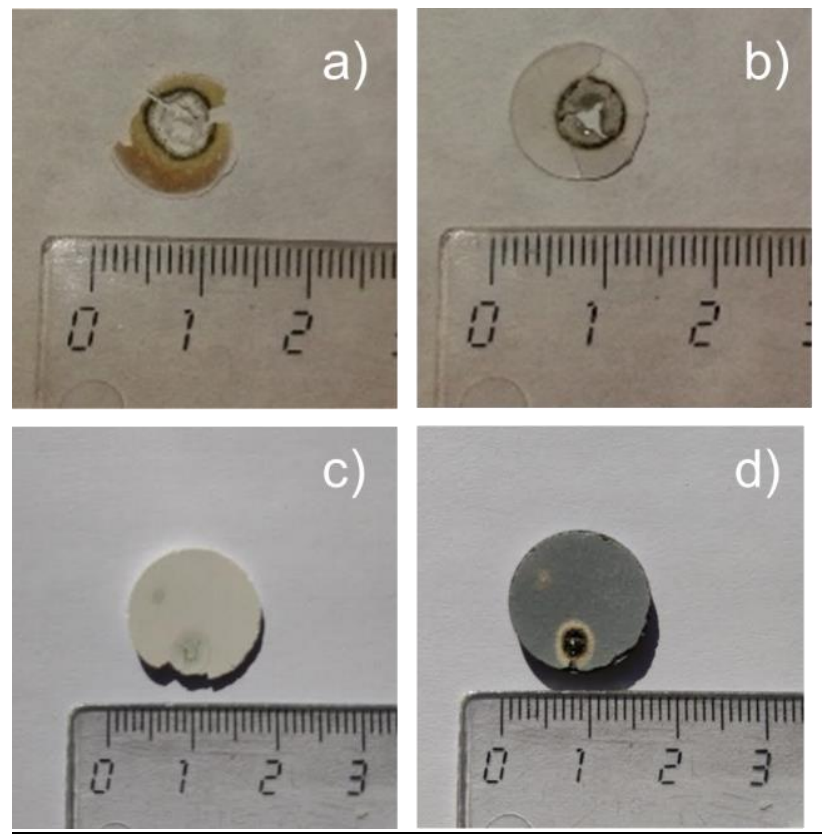

Figure S2.- Wafers after radiation: a) $\mathrm{CSH}^{0.5}$; b) $\mathrm{CSH}^{2.0}$; c) $\mathrm{C}_{2} \mathrm{SH}$; d) $\mathrm{FA}-\mathrm{C}_{2} \mathrm{SH}$ 

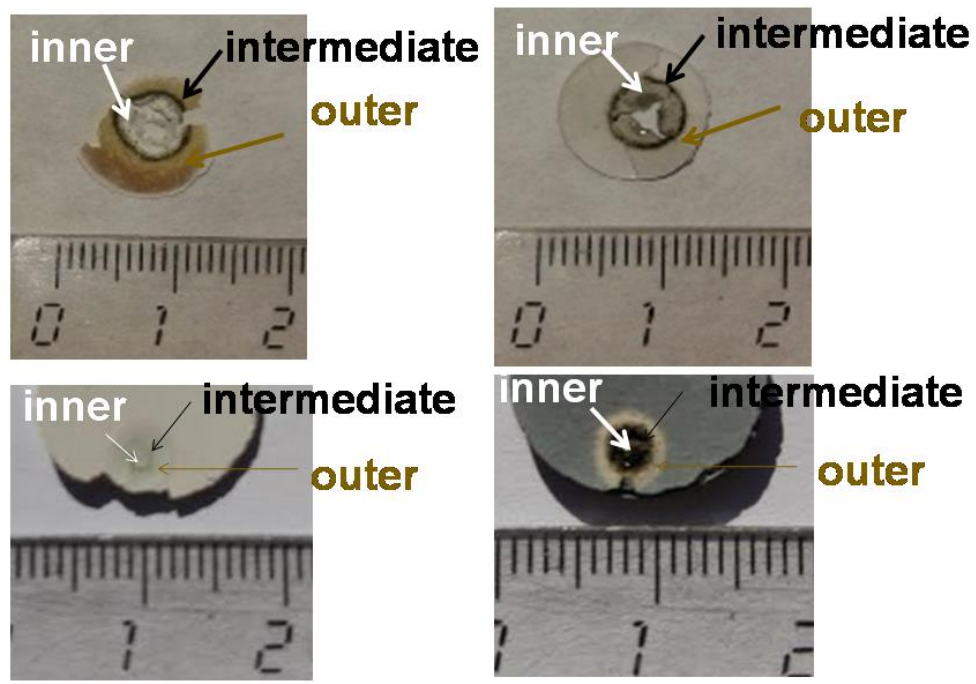

Fig. S3.- Wafers after radiation showing inner, intermediate and outer parts: a) $\mathrm{CSH}^{0.5}$; b) $\mathrm{CSH}^{2.0}$; c) ${ }_{\mathrm{C} 2 \mathrm{SH}}$; d) $\mathrm{FA}-\mathrm{C}_{2} \mathrm{SH}$ 